\title{
Numerical Modeling of Wet Plume to Understand Intraplate Volcanism in East Asia
}

\author{
CHANGYEOL LEE AND SOOHWAN YOO \\ Department of Earth System Sciences, Yonsei Univeristy \\ Seoul, Republic of Korea 03722 \\ changyeol.lee@yonsei.ac.kr
}

Intraplate volcanism in East Asia has been studied for decades but the genesis of the volcanism remains debated. Previous studies show that more than $60 \mathrm{wt} \%$ of the water bound to hydrous minerals in the lithospheric mantle of the Pacific plate can be transported deeper than a depth of 250 $\mathrm{km}$, which implies that the stagnant slab in the mantle transition zone may hold hydrous minerals. The geochemical studies showing the role of water in the magma generation support the potential contribution of the free water from the stagnant slab to the intraplate volcanism. If the free water dehydrated from the stagnant slab provides free water to the overlying mantle transition zone which is already partially hydrated, the wet plume by the additional hydration could occur. To evaluate the generation of the wet plume in the mantle transition zone by the additional hydration, we formulated 2-dimensional numerical models which consider the dehydation of the lithospheric mantle in the stagnant slab, porous flow of the free water expelled from the slab, hydration of the overlying mantle transition zone. Compared to previous studies, porous flow of the free water in the stagnant slab and mantle transition zone is newly considered. We quantitatively evaluate the effects of diverse parameters such as water solubility and mantle rheology on the genesis of the wet plume. We expect that this finding be another hypothesis for the generation of the wet plume, which can be tested by other geophysical/geochemical studies. 